\title{
Relationship emotional intelligence and personality traits with organizational commitment among Iranian nurses
}

Zahra Taherinejad ${ }^{1}$, Seyed Ahmad Ahmadi², Rozita Amani ${ }^{3}$, Mahdieh Sadat Khoshouei ${ }^{4}$

\author{
Journal of Research \& Health \\ Social Development \& Health Promotion \\ Research Center \\ Vol. 7, No. 1, Jan \& Feb 2017 \\ Pages: 614- 623. \\ DOI: 10.18869/acadpub.jrh.7.1.614 \\ Original Article
}

1. Department of Psychology, Faculty of Psychology and Educational Sciences, Islamic Azad University, Hamadan Branch, Hamadan, Iran

2. Department of Counseling, Faculty of Psychology and Educational Sciences, University of Isfahan, Isfahan, Iran

3. Department of Psychology, Faculty of Psychology and Educational Sciences, Buali Sina University, Hamadan, Iran

4. Correspondence to: Department of Psychology, Faculty of Psychology and Educational Sciences, University of Isfahan, Isfahan, Iran

Email: Khoshouei.mahdieh@gmail.com

Received: 6 Nov 2013

Accepted: 12 Sep 2014S

How to cite this article: Taherinejad Z, Ahmadi SA, Amani R, Khoshouei MS. Relationship emotional intelligence and personality traits with organizational commitment among Iranian nurses. J Research Health2017; 7(1): 614- 623.

\section{Introduction}

In the past three decades, organizational commitment has been of interest to researchers as one of the organizational attitudes. The organizational commitment refers to a psychological state that binds the individual to the organization (i.e. makes turnover less likely). Organizational commitment includes three commitments: affective (emotional attachment and devotion to work and desire to stay), continuance (perceived costs of leaving the organization and probability of not leaving), and normative (providing services and working as a duty, obligation and personal responsibility) [1].

Committed and loyal workforce that is compatible with organizational goals and values beyond responsibilities stated in the job description is considered a major factor in organizational efficacy. Not only such a workforce enhances performance and lowers rate of absenteeism, delay, and resignation, it but also elevates organizational social credibility. On the contrary, a workforce with a poor sense of loyalty, obligation and commitment, not only is not compatible with organizational goals, but also undermines 
spirit of cooperation by creating a culture of indifference toward organizational problems, and ultimately delay organizational success. Thus, in recent years, many researchers have sought to understand factors affecting employees' organizational commitment [2].

This issue has greater importance in the national health system and organization because nurses are among people that shoulder the responsibility of people's health and life, and sometimes are faced with incurable diseases and patients. Thus, they have to constantly deal with severe mental and physical pressures, which may lead to their dissatisfaction, resignation, and consequently, reduced organizational commitment [3]. Therefore, identifying factors affecting organizational commitment in nurses can help enhance quality of patient care. Accordingly, this study investigates two important factors affecting nurses' organizational commitment including emotional intelligence and personality traits.

Emotional intelligence is a subset of capabilities and skills that equip the person for effective compatibility with the environment and achievement of success in life [4], and includes the following components: emotional self-awareness (knowledge of oneself, emotions and what causes them), assertiveness (ability to openly express emotions, beliefs, and thoughts), self-regard (accepting oneself as a worthwhile person, respecting and loving oneself), self-actualization (attempt to realize one's own potentials), independence (attachment to others, without depending on them), empathy (ability to understand other people's feelings, and not being indifferent to them), social responsibility (asserting oneself as a cooperative and constructive person) interpersonal relationships (ability to establish and maintain relationships with others and influence them), reality-testing (understanding current situation, effort to maintain the right conditions and experience events), flexibility (ability to make emotions, thoughts and behaviors compatible with situations), problemsolving (ability to identify problems and create solutions), stress tolerance (resilience against stressful events and situations), impulse control (self-reservation and ability to control emotions and postpone success), optimism (positive attitude toward life), and happiness (ability to enjoy one's life and others, and satisfaction with life) [5].

The main five personality traits or factors include: neuroticism, extroversion, and openness to experience, agreeableness, and conscientiousness [6]. Neuroticism is experiencing such states as depression, anxiety, anger, insecurity and worry. Agreeableness involves having a polite, trustworthy, flexible, good-natured, cooperative, forgiving, compassionate and patient personality. Extroversion is to have a sociable, daring, team-playing, talkative, and ambitious personality [7]. Openness to experience is to have an imaginative, tradition-breaking (against conventions), inquisitive, and open-minded personality [8]. Conscientiousness implies discipline, making effort to succeed, self-discipline, farsightedness, and contemplation [9].

The following domestic and foreign studies have confirmed the relationship between emotional intelligence and organizational commitment: Ostovar and Amirzadeh Khatouni [10], Rezaian and Keshtegar [2], Aminbeidokhti and Kargar [11], Keshavarz [12], Moradi and Tohidy Ardahaey [13], Sarboland [14], Ghorbani and Bagheri Sani [15], Adeymos [16], Salami [17], Guleryuz, et al. [18], Gahan [19], and Rathi and Rastogi [20]. The following studies have shown that emotional intelligence is a predictor of organizational commitment: Kazemi et al. [21], Keshavarz [12], and Othman and Anugerah [22] because having a high level of emotional intelligence causes awareness and positive feeling for thoughts, feelings, and behaviors of oneself and others, identifying and managing one's feelings, and proper understanding and conveying them to others, leading to elevated organizational commitment [10].

Domestic and foreign studies have confirmed the relationship between personality traits 
and organizational commitment. For instance, openness to experience and conscientiousness are related to acceptance of work and professional problems [23], and organizational goals and values respectively [24]. High level of neuroticism leads to excessive attention to the inner world and lack of attention to environmental and organizational expectations such as commitment and loyalty [25].

For instance, a study on simple and multiple relationships between personality traits and professional commitment among nurses working in hospitals in Ahwaz showed the highest correlation coefficient between personality traits and emotional and normative types of commitment, and also stepwise regression analysis showed that extroversion, openness to experience and agreeableness play the biggest role in explaining the triple areas of organizational commitment [23]. According to a study by Parvin [26] on teachers, significant relationships were observed between neuroticism and emotional commitment, extroversion and emotional and normative commitments, openness to experience and emotional, continuance, and normative commitments, agreeableness and emotional commitment, and conscientiousness and emotional and normative commitments. In their study, Sharifi, et al [27] found significant relationshipsbetweenneuroticism, extroversion, agreeableness, and conscientiousness with emotional commitment, and neuroticism and conscientiousness with continuance commitment, and conscientiousness with normative commitment. Results obtained by Darbanian [7] showed that conscientiousness and openness to experience positively predict emotional commitment, openness to experience negatively predicts continuance commitment, conscientiousness and extroversion positively predict emotional commitment, and neuroticism negatively predicts emotional commitment. Kumar and Bakhshi [28] showed that openness to experience negatively predicts continuance and normative commitments. Extroversion was found the most valid and significant predictor of all three organizational commitment components. Conscientiousness positively predicts emotional and normative commitments. Agreeableness positively predicts normative commitment. Neuroticism is negatively related to emotional commitment, and positively to continuance and normative commitments. Erdheim et al. study [29] in a car manufacturing company in America showed significant relationships between extroversion and emotional and continuance commitments, and between agreeableness and normative commitment. Some studies have demonstrated the relationship of personality traits such as introversion and extroversion with organizational commitment (Cammileri [30], Jahangiri et al. [31]). For instance, results obtained by Bahrami, et al [32], Gelade [33], and Khdabakhshi [34] showed that extrovert people have greater organizational commitment compared to introvert people because extroverts are able to establish social relationships with others, and receive various rewards at work, which leads to their increased organizational and professional attachment and commitment [23].

Although many foreign and Iranian authors have emphasized the important role of emotional intelligence and personality traits in organizational workforce commitment, including nurses, the effects of dimensions of personality traits and especially dimensions of emotional intelligence on organizational commitment have been overlooked. Thus, this study aims firstly to investigate the relationships between organizational commitment with emotional intelligence and personality traits, and then investigate power of personality traits and emotional intelligence in predicting organizational commitment.

\section{Method}

This study was conducted on a population of all nurses working in private and public hospitals in Isfahan of Iran, 2013. Study participants were selected using a multistage random sampling. First, 4 hospitals were selected from private and public hospitals in Isfahan, and then 280 nurses was selected from different 
departments in these hospitals. Tabachnich and Fidell equation (based on number of predicting variables) was used $(\mathrm{N}>50+8 \mathrm{~m})$ to determine sample size. Accordingly, in the present study, there are 20 predicting variables $(15$ components of emotional intelligence, and 5 personality traits). Thus minimum sample size required was 210 participants, but 280 were selected, which exceeds the recommended sample size [35]. According to the study objectives, three questionnaires were used as follows:

1) Bar-On emotional intelligence inventory: This questionnaire contains 133 items with 5 composite scales and 15 subscales or components (emotional self-awareness, assertiveness, self-regard, self-actualization, independence, empathy, social responsibility, interpersonal relationships, reality testing, flexibility, problem solving, stress tolerance, impulse control, optimism, and happiness). Scoring is based on Likert method (never, rarely, occasionally, often, and always) from 1 to 5 marks. Some items are scored positively and some negatively. Bar-On reported mean reliability as 0.85 after one month and 0.75 after 4 months at test-retest of emotional intelligence. In Iran, psychometric characteristics of this questionnaire were also assessed. In a study by researchers, 8 factors out of 13 tested in a North American sample were found valid in Iran using exploratory factor analysis [5]. For the 90-item version of this questionnaire, researchers found Cronbach's alpha, Spearman-Brown, Gattman, and retest coefficients $0.93,0.90,0.90$, and 0.85 , respectively [36].

2) Costa and McCrae 5-factor Neo personality inventory: This questionnaire contains 60 items, with 5 dimensions of extroversion, neuroticism, openness, agreeableness (flexibility) and conscientiousness. Five-point answers range from totally disagree, disagree, no comment, agree, to totally agree, scoring from 0 to 4 marks. Some items are scored in reverse from 4 to 0 [5].

3) Allen and Meyer Organizational commitment inventory: This questionnaire contains 24 items, assessing 3 dimensions of organizational commitment: emotional, continuance, and normative. There are 7 options from totally agree ( 7 marks) to totally disagree (1 mark). Scoring is reversed in some items. Higher scores indicate greater organizational commitment [37-38]. Validity [37] and reliability [38] of this questionnaire have been confirmed domestically.

At descriptive level, mean and standard deviation, and at inferential level, Pearson correlation coefficient was used to determine emotional intelligence and personality traits relationship with organizational commitment, and multivariate regression to decide prediction of organizational commitment by emotional intelligence and personality traits. Analyses were performed in SPSS-18 software.

\section{Results}

Table 1 presents demographic details of participants, including sex, age, education, recruitment status, work experience and marital status. Accordingly, most of the participants were younger than 30 years old, female, with bachelor's degree education, with contract employment, with less than 10 years of work history, and married.

Descriptive results (mean and standard deviation), organizational commitment, emotional intelligence and personality traits are presented in Table 2 .

Pearson correlation coefficient was used to assess the first study goal, the relationship between emotional intelligence and organizational commitment, which showed a positive and significant relationship between organizational commitment and dimensions of emotional intelligence: assertiveness, selfregard, independence, social responsibility, problem-solving, stress tolerance, impulse control, and optimism (Table 3). However, no significant relationship was found between organizational commitment and other dimensions of emotional intelligence such as self-awareness, reality testing, interpersonal relationships, flexibility, empathy, and happiness.

Pearson correlation coefficient was used to 
Table 1 Demographic characteristic for sample group

\begin{tabular}{|c|c|c|c|}
\hline \multicolumn{2}{|c|}{ Demographic variables } & $\mathrm{f}$ & Percent \\
\hline \multirow{6}{*}{$\begin{array}{l}\text { Educational } \\
\text { status }\end{array}$} & Under Diploma & 1 & 0.4 \\
\hline & Diploma & 6 & 2.1 \\
\hline & Associate of Science & 9 & 3.2 \\
\hline & Bachelor of Science & 227 & 81.1 \\
\hline & Master of Science & 16 & 5.7 \\
\hline & No response & 21 & 7.5 \\
\hline \multirow{3}{*}{$\begin{array}{l}\text { Recruitment } \\
\text { status }\end{array}$} & Official & 34 & 12.1 \\
\hline & Contractual & 231 & 82.5 \\
\hline & No response & 15 & 5.4 \\
\hline \multirow{4}{*}{$\begin{array}{c}\text { Work } \\
\text { experience }\end{array}$} & Under 10 & 207 & 73.9 \\
\hline & $11-20$ & 38 & 13.6 \\
\hline & $21-30$ & 14 & 5 \\
\hline & No response & 21 & 7.5 \\
\hline \multirow{3}{*}{$\begin{array}{l}\text { Marital } \\
\text { status }\end{array}$} & Married & 91 & 32.5 \\
\hline & Single & 178 & 63.6 \\
\hline & No response & 11 & 3.9 \\
\hline \multirow{4}{*}{ Age } & Under 30 & 149 & 53.2 \\
\hline & $31-40$ & 86 & 30.7 \\
\hline & $41-50$ & 28 & 10 \\
\hline & No response & 17 & 6.1 \\
\hline \multirow{3}{*}{ Gender } & Female & 235 & 83.9 \\
\hline & Male & 31 & 11.1 \\
\hline & No response & 14 & 5 \\
\hline
\end{tabular}

Table 2 Means (M), Standard Deviations (SD) for organizational commitment, emotional intelligence and personality traits

\begin{tabular}{|c|c|c|c|}
\hline & Variable & M & SD \\
\hline \multirow{16}{*}{$\begin{array}{l}\text { Emotional } \\
\text { intelligence }\end{array}$} & Total & 322.364 & 30.478 \\
\hline & Emotional self-awareness & 21.464 & 3.112 \\
\hline & Reality-testing & 20.564 & 3.898 \\
\hline & Interpersonal relationship & 23.429 & 2.860 \\
\hline & Flexibility & 19.139 & 3.426 \\
\hline & Self-expression & 19.289 & 3.417 \\
\hline & Self-regard & 22.704 & 3.205 \\
\hline & Self-actualization & 21.943 & 3.577 \\
\hline & Independence & 20.971 & 3.642 \\
\hline & Empathy & 23.714 & 2.753 \\
\hline & Social responsibility & 23.946 & 2.715 \\
\hline & Problem-solving & 22.768 & 2.716 \\
\hline & Stress tolerance & 19.643 & 3.409 \\
\hline & Impulse control & 18.325 & 4.749 \\
\hline & Optimism & 22.325 & 3.149 \\
\hline & Happiness & 22.139 & 3.469 \\
\hline $\begin{array}{l}\text { Organizational } \\
\text { commitment }\end{array}$ & $\begin{array}{l}\text { Organizational } \\
\text { commitment }\end{array}$ & 4.044 & 0.702 \\
\hline \multirow{5}{*}{ Personality traits } & Neuroticism & 21.493 & 6.384 \\
\hline & Extraversion & 28.971 & 5.340 \\
\hline & Openness to experience & 24.543 & 4.280 \\
\hline & Agreeableness & 30.389 & 5.435 \\
\hline & Conscientiousness & 33.614 & 5.871 \\
\hline
\end{tabular}


assess the second study goal, the relationship between personality traits and organizational commitment. According to Table 3, there was a positive and significant relationship between organizational commitment and extroversion and conscientiousness. But, no significant relationship was found between organizational commitment and other dimensions of personality traits such as neuroticism, openness to experience, or agreeableness.

The third study objective, assessing the

Table 3 Correlation coefficient result between emotional intelligence and personality traits with organizational commitment

\begin{tabular}{|c|c|c|c|c|}
\hline & \multirow{2}{*}{ Variable } & \multicolumn{3}{|c|}{ Organizational commitment } \\
\hline & & $\mathrm{r}^{2}$ & Sig. & \\
\hline \multirow{15}{*}{$\begin{array}{r}\text { Emotional } \\
\text { intelligence }\end{array}$} & Emotional self-awareness & 0.053 & 0.003 & 0.375 \\
\hline & Reality-testing & 0.106 & 0.011 & 0.077 \\
\hline & Interpersonal relationship & 0.081 & 0.006 & 0.175 \\
\hline & Flexibility & 0.091 & 0.008 & 0.128 \\
\hline & Self-expression & $0.140 *$ & 0.020 & 0.019 \\
\hline & Self-regard & $0.153 *$ & 0.023 & 0.010 \\
\hline & Self-actualization & 0.058 & 0.003 & 0.334 \\
\hline & Independence & $0.127^{*}$ & 0.016 & 0.033 \\
\hline & Empathy & 0.038 & 0.001 & 0.524 \\
\hline & Social responsibility & $0.135 *$ & 0.018 & 0.024 \\
\hline & Problem-solving & $0.238 * *$ & 0.057 & 0.001 \\
\hline & Stress tolerance & $0.229 * *$ & 0.052 & 0.001 \\
\hline & Impulse control & $0.132 *$ & 0.017 & 0.027 \\
\hline & Optimism & $0.156^{* *}$ & 0.024 & 0.009 \\
\hline & Happiness & 0.106 & 0.011 & 0.076 \\
\hline \multirow{5}{*}{$\begin{array}{l}\text { Personality } \\
\text { traits }\end{array}$} & Neuroticism & -0.105 & 0.011 & 0.079 \\
\hline & Extraversion & $0.163 * *$ & 0.026 & 0.006 \\
\hline & Openness to experience & -0.049 & 0.002 & 0.417 \\
\hline & Agreeableness & 0.017 & 0 & 0.772 \\
\hline & Conscientiousness & $0.122 *$ & 0.015 & 0.041 \\
\hline
\end{tabular}

power of emotional intelligence in predicting organizational commitment, was determined using concurrent regression analysis.

According to Table 4, given statistic $t$ and significance level, of the 15 components, only self-awareness $\quad(\mathrm{p}<0.05, \quad \mathrm{t}=-2.32)$, problem-solving $(\mathrm{p}<0.05, \mathrm{t}=2.197)$, and stress tolerance $(\mathrm{p}<0.05, \mathrm{t}=2.353)$ showed significant relationships with organizational commitment. Power of personality traits in predicting organizational commitment (the final study objective) was assessed using concurrent regression analysis.

According to Table 4, given statistic $\mathrm{t}$ and significance level, the five personality traits, not showed significant relationships with organizational commitment. But, given standard $\beta$ coefficients, extroversion had the highest predicting power and openness to experience had the lowest.

\section{Discussion}

The first study finding showed a positive and significant relationship between organizational commitment and dimensions of emotional intelligence: assertiveness, selfregard, independence, social responsibility, problem-solving, stress tolerance, impulse control, and optimism, which agrees with domestic studies by Ostovar and Amirzadeh Khatouni [10], Rezaian and Keshtegar [2], Aminbeidokhti and Kargar [11], Keshavarz [12], Moradi and Tohidy Ardahaey [13], Sarboland [14], Ghorbani and Bagheri Sani 


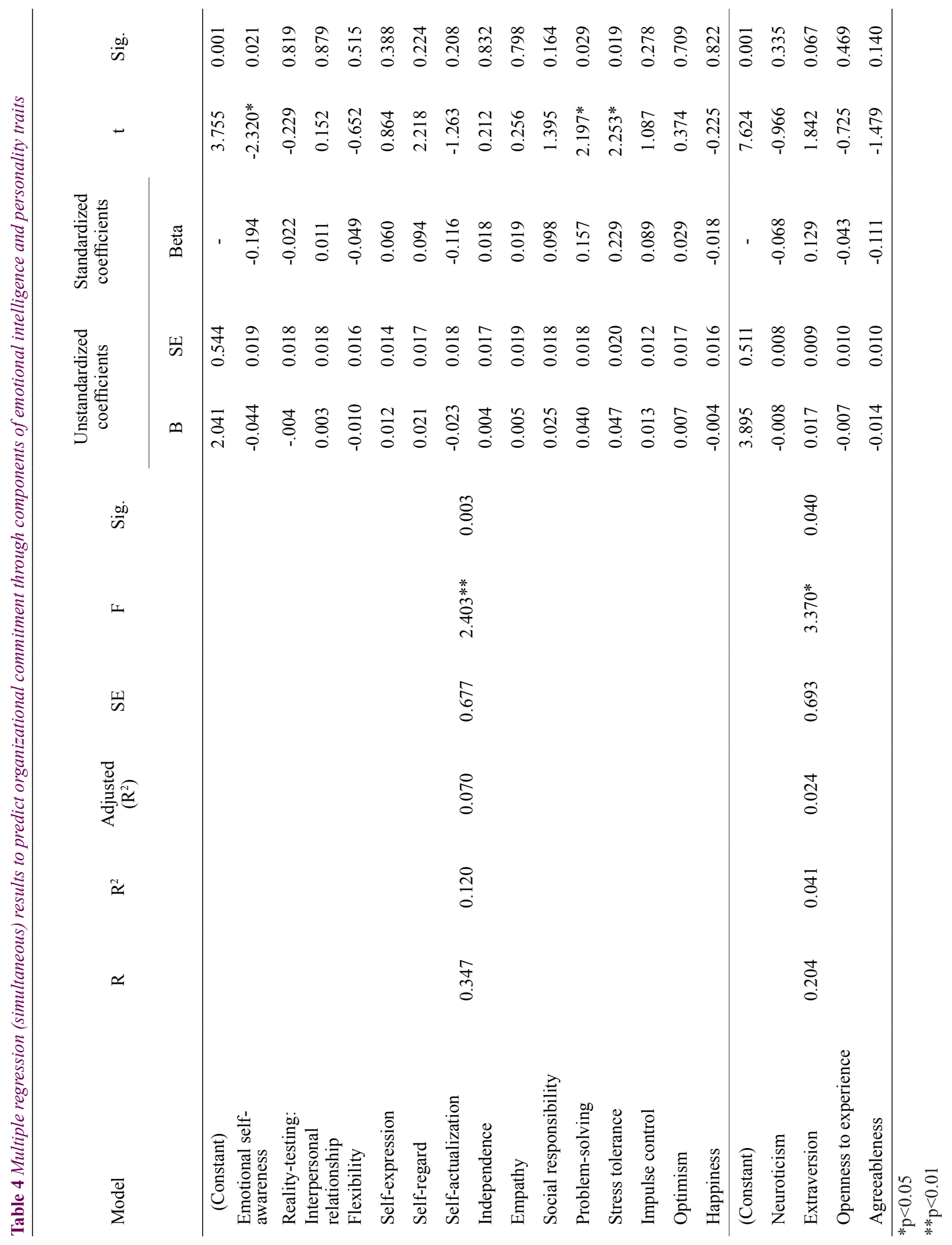


[15], Adeymos [16], Salami [17], Guleryuz, et al. [18], Gahan [19], and Rathi and Rastogi [20]. The agreement between results can be attributed to common tools used in most studies (in emotional intelligence and organizational commitment). Moreover, one of the components of emotional intelligence was self-awareness. Increased self-awareness of people may help organizational continuous success and lead to greater commitment.

The second finding showed the positive and significant relationship of organizational commitment with extroversion and conscientiousness. This result agrees with some studies, but disagrees with others. For instance, the present study result agrees with a study by Parvin [26] showing a negative relationship between emotional commitment and neuroticism, with a study by Darbanian [7] showing a negative relationship between continuance commitment and neuroticism, and with Cammileri [30], Jahangir, et al [31], Bahrami, et al [32], Gelade [33], and Khodabakhsh [34] showing a positive relationship between organizational commitment and extroversion. However, it disagrees with results of studies by Kumar and Bakhshi [38] showing a negative relationship between openness to experience and continuance and normative commitments, and with Sharifi and Salami [27] showing a relationship between conscientiousness and emotional commitment. The disagreement may be attributed to differences in the study population. Although explaining the relationship between personality traits and organizational commitment requires further studies, to explain the positive relationship of extroversion with emotional and normative commitments, it can be asserted that since extroverts are able to establish social relationships, they receive wide variety of rewards at work, and this leads to increased attachment and commitment toward the job and organization, and organizational commitment and therefore, productivity is increased [23].

The third study finding showed that components of emotional intelligence are able to predict organizational commitment, which concurs with previous studies in this area, including Keshavarz [12], Kazemi et al. [21], Othman and Angerach [22] confirming power of emotional intelligence in predicting organizational commitment. To explain, it should be noted that high level of emotional intelligence increases awareness and positive feeling toward thoughts, feelings and behaviors of oneself and others, recognition and management of one's feelings and understanding and conveyance of these feeling to others, leading to higher organizational commitment [10].

The fourth study result not confirmed power of personality traits in predicting organizational commitment, which disagrees with results found by Kumar and Bakhshi [28] showing prediction of organizational commitment by personality traits. According to researcher's search, no other study has been conducted in this area. Thus, further studies are required for explaining this relationship. However, the relationship with openness to experience can be explained by the fact that people with high scores in openness to experience have greater power in accepting various professional problems at work [23]. Similarly, since conscientious people have the tendency to get involved in their work, they can be expected to have greater acceptance of organizational goals and values [24]. Regarding neuroticism, people with negative emotions such as anger, anxiety and stress are inadequately stable, and are so involved in their own mental problems that neglect events in the workplace, which makes them unable to meet environmental and organizational expectations [25].

\section{Conclusion}

Generally, the present study correlation results showed a positive and significant relationship between organizational commitment and dimensions of emotional intelligence, including assertiveness, selfrespect, independence, social responsibility, problem-solving, stress tolerance, impulse control, and optimism. Furthermore, there is 
a positive and significant relationship between organizational commitment and extroversion and conscientiousness. Regression analysis results confirmed power of emotional intelligence in predicting organizational commitment.

Study limitations included conducting the study in nurses in Isfahan city. It is therefore recommended thatinsimilarstudies beconducted in other provinces and other organizations. In the present study, the relationship of emotional intelligence and personality traits with organizational commitment was assessed. It is recommended that future studies examine this relationship together with demographic parameters. In addition, given the relationship between organizational commitment and emotional intelligence and personality traits, it is recommended that emotional intelligence and personality traits be assessed using employment tests in selecting the participants.

\section{Acknowledgements}

The authors acknowledge the nurses of Isfahan city for participation in this study.

\section{Contribution}

\section{Study design: ZT, MS Kh}

Data collection and analysis: ZT, SAA, RA, MSKh

Manuscript preparation: ZT, MSKh

\section{Conflict of Interest}

The authors declare that they have no competing interests.

\section{Funding}

The author (s) received no financial support for the research, authorship and/or publication of this article.

\section{References}

1- Pasha G, Khodadadi F. Relationship between personality traits and job characteristics with organizational commitment in Ahvaz water and power organization. Journal of New Findings in Psychology2008; 2(6): 54-65.

2- Rezaian A, Keshtegar AA. The relationship between emotional intelligence and organizational commitment.
Journal of Business Management Perspective2008; 7(27): 27-39.

3- Bakhshi Soreshjani L. Relationship between emotional intelligence and mental health among teachers, nurses and employees. New Findings in Psychology2010; 5(13): 23-33.

4-Sobhaninejad M, Yozbashi A. Emotional intelligence and management on organization: Theoretical background, training method and assessments tools. Tehran: Yastaron publication; 2009.

5- Fathi Ashtiani A, Dastani M. Psychological tests personality and mental health. Tehran: Besat publication; 2009.

6- McCrae RR. Social consequences of experiential openness. Psychol Bull1996; 120(3): 323-37.

7-Darbanian M.An investigation of simple and multiple relationships among five-factor model of personality, job involvement and organizational commitment in employees of the industrial corporations located at the Khorasan science and technology park incubator. [dissertation]. Isfahan: University of Isfahan 2012; pp: 110 .

8- Clarke S, Robertson IT. A meta-analytic review of the big five personality factors and accidents involvement in occupational and non-occupational settings. J Occup Organ Psychol2005; 78(3): 355-36. 9- Liao CS, Lee CW. An empirical study of employee job involvement and personality traits: The case of Taiwan. Int J Health Econ Manag2009; 3(2): 22-36.

10- Ostovar S, Amirzadeh Khatouni M. Investigation into the relationship among emotional intelligence, job satisfaction and organizational commitment of a private company personnel. Journal of New Approaches in Educational Administration2008; 1(2): 23-38.

11- Aminbeidokhti AA, Kargar H. The relationship between emotional intelligence and job satisfaction with organizational commitment among secondary school teachers in Yazd city. Journal of Educational Leadership \& Administration2013; 4(3): 19- 37.

12- Keshavarz L. Designing relationship model of emotional intelligence and organizational commitment of Tehran municipality sport organization. Management of Sport and Movement Sciences2013; 2(4): 47-55.

13-Moradi H, Tohidy Ardahaey F. The role of emotional intelligence in organizational commitment. 2011. Available at URL: http://ssrn.com/abstract=1848523. Accessed May 21, 2011.

14- Sarboland K. Assessment of the relationship between emotional intelligence and organizational commitment of employees: a case study of Tax Affairs offices, Iran. Journal of Basic and Applied Scientific Research2012; 2(5): 5164-8. 
15- Ghorbani M, Bagheri Sani SA. Emotional intelligence and personnel organizational commitment. Middle East J Sci Res2012; 11(8): 1100-15.

16- Adeymos A. Emotional intelligence and the relationship between job satisfaction and organizational commitment of employee in public details in state Nigeria. Pakistan Journal of Social Sciences2000; (40): 324-30.

17- Salami So. Demographic and psychological factors predicting organizational commitment among industrial workers. Anthropologist2008; 10(1): 31-8.

18- Guleryuz G, Guney S, Aydine E, Asan O. The mediating effect of job satisfaction be-tween emotional intelligence and organizational commitment of nurses. International Journal of Nursing Studies2008; 45(11), 16- 25.

19- Gahan B. A study of the relationship between emotional intelligence and individual performance in an inbound North American call center. United States Arizona: Grand Canyon University; 2012.

20- Rathi N, Rastogi R. Assessing the relationship between emotional intelligence, occupational selfefficacy commitment and organizational. Journal of the Indian Academy of Applied Psychology2009; 35: 93102.

21- Kazemi Y, Mehdinezhad V, Jamali R. Relationship of managers' emotional intelligence with their selfcontrol and organizational commitment. Journal of Management and Development Process2012; 24(4): 75-92.

22- Othman S, Anugerah R. Effects of emotional intelligence and career commitment on career success. 2009. Malaysian Management Review2009; 37(1): 4652.

23- Jazayeri SZ, Naami Aaz, Shokrkon H, Taghi Pour M. An investigation of simple and multiple relationships between personality traits and professional commitment among nurses in some Ahvaz hospitals. Journal of Education and Psychology2006; 13(3): 189-208.

24- Hogan J, Johnson R, Briggs S. Handbook of personality psychology. San Diego, CA: Academic press; 1997.

25- Organ DW, Lingl A. Personality, satisfaction and organizational citizenship behavior. J Soc Psychol1995, 135(3): 339-50.

26- Parvin A. Relationship between the big five personality constructs and organizational of guidance and high school teachers and Islam- Abad Gharb. [dissertation]. Isfahan: University of Isfahan 2009; P: 100.

27- Sharifi S, Salami G, Ahmadi A. Study of the relationship between the personality characteristics and the organizational commitment of the principals and teachers of elementary, secondary and high schools of
Khansar. Journal of New Approaches in Educational Administration2008; 1(4): 81- 106.

28- Kumar K, Bakhshi A. The five-factor model of personality and organizational commitment: Is there any relationship? Humanity \& Social Sciences Journal2010; 5(1): 25- 34.

29- Erdheim J, Wang M, Zickar MJ. Linking the big five personality constructs to organizational commitment. Pers Individ Dif2006; 41(5): 959-70.

30- Cammileri E. Some antecedents of organizational commitment: Results from an information systems public sector organization. Bank of Valletta Review2002; 25(1): 1-29.

31- Jahangir N, Akbar MM, Haq M. Organizational citizenship behavior: It's nature and antecedents. BRAC University Journal2004; 1(2): 75-85.

32- Bahrami MA, Emamrezaei A, Sattar E, Ranjbar Ezzatabadi M, Dehghani Tafti A. The comparative survey of organizational commitment based on personal traits: a case study on nurses in Yazd training hospitals. Journal of Tolooe Behdasht2010; 9(2,3): 44- 59.

33- Gelade GA. National differences in organizational commitment: effect of economy, product of personality or consequences of culture? J Cross Cult Psychol2006; 37(5): 542-56

34- Khodabakhshi M. Organizational commitment with personality type (Myers-Brigg's) in bank staff of Iran. Journal of Basic and Applied Scientific Research2012, 2(9): 9460-5.

35- Tabachnick BG, Fidell LS. Using multivariate statistics (3rd edition). New York: Harper collins; 1999.

36- Golparvar M, Aghaie A, Khaksar F. Relationship between emotional intelligence and their components with job performance and career advancement. Knowledge \& Research in Applied Psychology2006; 25(7): 75- 106.

37- Abili Kh, Nastezaie N. Surveying the relationship between psychological empowerment and organizational commitment in nursing staff. Tolooe Behdasht2010, 8(1,2): 26- 39.

38- Khanifar H, Moghimi SM, Jandaghi GHR, Zarvandi N. Analysis of relation between elements of trust and organizational commitment of personnel (social welfare organization of Qom state and education organization of Qom state). Journal Public Administration2009; 1(2): 3- 18. 